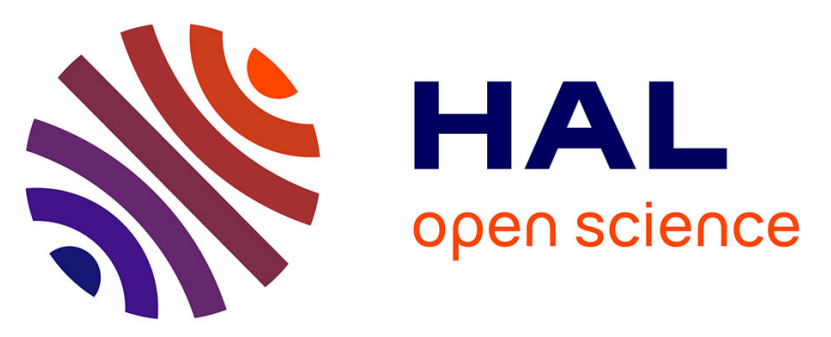

\title{
Surface Rupture and Slip Distribution of the 1940 Imperial Valley Earthquake, Imperial Fault, Southern California: Implications for Rupture Segmentation and Dynamics
}

Thomas. K. Rockwell, Yann Klinger

\section{To cite this version:}

Thomas. K. Rockwell, Yann Klinger. Surface Rupture and Slip Distribution of the 1940 Imperial Valley Earthquake, Imperial Fault, Southern California: Implications for Rupture Segmentation and Dynamics. Bulletin of the Seismological Society of America, 2013, 103 (2A), pp.629-640. 10.1785/0120120192 . insu-01303797

\section{HAL Id: insu-01303797 https://hal-insu.archives-ouvertes.fr/insu-01303797}

Submitted on 18 Apr 2016

HAL is a multi-disciplinary open access archive for the deposit and dissemination of scientific research documents, whether they are published or not. The documents may come from teaching and research institutions in France or abroad, or from public or private research centers.
L'archive ouverte pluridisciplinaire HAL, est destinée au dépôt et à la diffusion de documents scientifiques de niveau recherche, publiés ou non, émanant des établissements d'enseignement et de recherche français ou étrangers, des laboratoires publics ou privés. 


\title{
Surface Rupture and Slip Distribution of the 1940 Imperial Valley Earthquake, Imperial Fault, Southern California: Implications for Rupture Segmentation and Dynamics
}

\author{
by Thomas K. Rockwell and Yann Klinger
}

\begin{abstract}
We analyzed high-resolution aerial photography taken soon after the 1940 Imperial Valley earthquake to provide a higher resolution distribution of displacement with which to test variation in lateral slip, to compare the difference in making slip measurements parallel to local or regional fault strike, and to compare to the seismological properties of the 1940 earthquake. We performed 648 new measurements of displacement along the $15 \mathrm{~km}$ section of rupture for which imagery exists. Nearly $7 \mathrm{~m}$ of maximum displacement occurred within $2 \mathrm{~km}$ of the border, which was higher than previous estimates, with an average slip of about $5.5 \mathrm{~m}$ for this section. There is considerable variation along the strike, on the order of $1 \mathrm{~m}$ of variability across hundreds of meters of lateral distance in the section of high slip; areas of larger offset tend to have greater variations in displacement. From these observations, we conclude that lateral variability of displacement typically varies by as much as $30 \%$ along a rupture section. The difference in measured displacement at a specific point along the fault varied considerably when using local fault strikes versus that of regional or average fault. However, the overall average difference between measurements for different azimuths at a specific point is only $-0.01 \pm 0.19 \mathrm{~m}$, indicating that this is not a major issue if one is consistent. Finally, abrupt changes in displacement along a strike are apparently related to segmentation and the rupture process, and mimic the subevents, as documented through seismological methods. The largest moment pulse corresponds to the section south of the border, whereas the greatest displacements occurred north of the border where the average moment release is inferred to be less. We explain this by inferring a strong, shallow asperity in the border region, consistent with 1979 rupture event beneath it.
\end{abstract}

Online Material: High-resolution imagery of the 1940 rupture with locations of offset measurements, and tabulated offset values.

\section{Introduction}

Detailed mapping of surface ruptures and their associated slip distributions resulting from large earthquakes provide fundamental observations that guide understanding of many aspects of the earthquake process. The amount of displacement relative to the earthquake magnitude and overall length of a rupture provide insights into scaling relationships, in addition to providing a basis for forecasting the size and extent of future ruptures (Wells and Coppersmith, 1994). The width of steps and jogs relative to rupture terminations and changes in displacement provide predictive information on the locations of the likely endpoints of future ruptures (Wesnousky, 2008), and the abrupt steps in the amount of displacement could provide insights into the segmentation of a fault or individual rupture (Haeussler et al., 2004; Klinger,
2010). Resolving lateral variations in displacement may also allude to aspects of the rupture process or to the physical properties of the fault zone.

Despite more than a century of ruptures following the 1891 Nobi and 1906 San Francisco earthquakes, where scientists recognized the intimate relationship between surface faulting and the earthquake itself, mapping of rupture distribution after larger earthquakes has only been systematically accomplished in recent decades (e.g., the $1957 M_{\mathrm{w}} 8.1 \mathrm{Gobi}$ Altai earthquake [Kurushin et al., 1997]; $1968 M_{\mathrm{w}} 6.6$ Borrego Mountain earthquake [Clark, 1972]; the $1979 M_{\mathrm{w}} 6.6$ Imperial Valley earthquake [Sharp, 1982]; the $1987 M_{\mathrm{w}} 6.6$ Superstition Hills earthquake [McGill et al., 1989]; the 1992 $M_{\mathrm{w}} 7.3$ Landers earthquake [Sieh et al., 1993]; the 1999 
$M_{\mathrm{w}} 7.1$ Hector Mine, $M_{\mathrm{w}} 7.4$ Izmit, $M_{\mathrm{w}} 7.1$ Duzce, and $M_{\mathrm{w}} 7.8$ Taiwan earthquakes [Chen et al., 2001; Barka et al., 2002; Treiman et al., 2002]; the $2002 M_{\mathrm{w}} 7.9$ Denali earthquake [Haeussler et al., 2004], and the $2010 M_{\mathrm{w}} 7.2$ MayorCucapa earthquake [Fletcher et al., 2010] among them), and to date, only a few dozen earthquakes have been mapped in sufficient detail to be useful in describing the fundamental properties of the rupture (Wesnousky, 2008). Because of recent technological advancements and greater availability of archived aerial imagery, some early instrumental ruptures are being mapped, especially those in dry environments (Kurushin et al., 1997; Kondo et al., 2005; Klinger et al., 2011; Salisbury et al., 2012), long after the actual occurrence of the rupture. Recent ruptures are also now being mapped in unprecedented detail by the application of new techniques, such as interferometric synthetic aperture radar (InSAR) and light detection and ranging (LiDAR; Peltzer et al., 1999; Wright et al., 2001; Çakir et al., 2003; Oskin et al., 2012). Nevertheless, the overall number of well-mapped ruptures is small, so there is a need to increase these observations.

In this work, we present new measurements for the 1940 surface rupture along the Imperial fault in southern California (Fig. 1), obtained through the use of high-resolution aerial photography. We measured 648 new displacements along $15 \mathrm{~km}$ of the 1940 rupture, which is the extent of highresolution aerial photography for this rupture. Measurements are mostly on long, linear cultural features and crop rows, and are spaced between one to tens of meters apart, allowing for highly detailed resolution of variations in lateral slip (see the (E) electronic supplement for the complete set of interpreted imagery and observations). We combine these new data with slip measurements obtained by J. P. Buwalda (unpublished notes taken after the 1940 rupture on file at Caltech, and in Trifunac and Brune, 1970) and by Sharp et al. (1982) for additional cultural features north and south of the border. We also used an offset line of trees $100 \mathrm{~m}$ south of the border (reported in Thomas and Rockwell, 1996) and a telephone pole alignment that we surveyed near Taumalipas, formerly Cucapa. These observations were used to produce a higher resolution and more complete distribution of lateral displacement for the 1940 surface rupture.

We show that slip measurements reported for the 1940 earthquake underestimate the maximum reported displacement (Sharp et al., 1982), as field measurements after the earthquake were made on widely spaced cultural features, such as roads and canals, and the zone of maximum displacement was not visited. These observations point to the need for field geologists to over sample displacement data after an

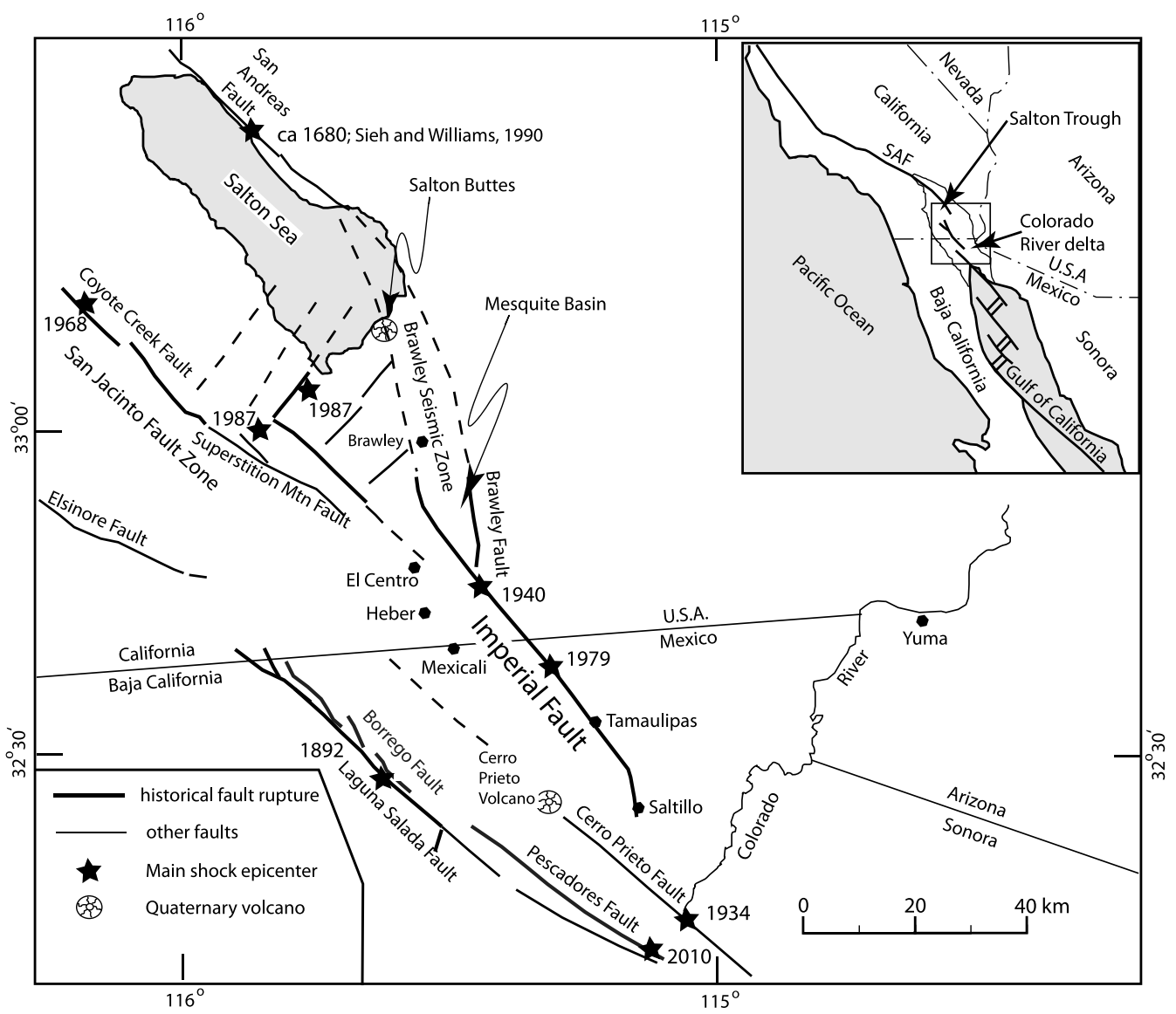

Figure 1. Location map of the Imperial fault in southern California and northern Baja California. It is worthy to note that the 1940 earthquake ruptured the entire length of the Imperial fault, whereas the 1979 earthquake only ruptured the northern third but nucleated south of the border. 
earthquake, rather than perform random, widely spaced measurements that may not represent the actual coseismic slip distribution. We also show that local displacement measurements varied considerably along a strike, a feature that has now been documented for several recent earthquakes (Rockwell et al., 2002; Treiman et al., 2002; Klinger et al., 2005), and we tested estimates of displacement measured parallel to the average fault strike versus those measure along the local fault strike, as would be conducted by a field geologist. Finally, we discuss the overall shape of the slip-distribution curve and its apparent segmentation relative to the complex rupture process that is inferred from seismological analysis of the mainshock sequence (Trifunac and Brune, 1970; Doser, 1990).

\section{The 1940 Earthquake and Its Setting}

On 18 May 1940, an $M_{\mathrm{w}} 7.0$ earthquake struck Imperial Valley on a previously unknown fault, thereafter named the Imperial fault, producing surface rupture for nearly $60 \mathrm{~km}$ through farmlands both north and south of the international border between the U.S. and Mexico (Buwalda and Richter, 1941; Richter, 1958; Sharp et al., 1982). Thirty-nine years later, the northern third of the fault ruptured again in October 1979 (Sharp, 1982). Geodetic studies have shown that the Imperial fault transfers $\sim 70 \%-80 \%$ of the relative motion between the Pacific and North American plates (Bennett et al., 1996), marking this fault as the main plate boundary structure crossing the international border. To the south near the Cerro Prieto volcano, the Imperial fault steps right nearly $15 \mathrm{~km}$ (releasing step, spreading center) to the Cerro Prieto fault, which ruptured in an $M_{\mathrm{w}} 7.1$ earthquake in 1934. The north end of the 1940 rupture terminated in Mesquite Basin, a closed depression between the Imperial and Brawley faults (Fig. 1). The Brawley Seismic Zone represents a complex zone of strain transfer to the southern San Andreas fault, which, along with the San Jacinto fault, are the main plate boundary elements to the north. It is noteworthy that the most recent large earthquakes on the southern San Andreas and Clark faults (the Clark fault is the main strand of the southcentral San Jacinto fault) occurred centuries ago: 22 November 1800 for the San Jacinto fault (Salisbury et al., 2012) and ca. 1700 for the southern San Andreas fault (Sieh and Williams, 1990). In contrast, the Elsinore-Laguna Salada fault zone has produced several large earthquakes in the past three centuries (Fig. 1), including an $\sim M 7$ in ca. 1750 in the Coyote Mountains along the southernmost Elsinore fault (Rockwell, 1990), an $M_{\mathrm{w}} 7.1$ in 1892 along the Laguna Salada fault (Mueller and Rockwell, 1995), and most recently, the $M_{\mathrm{w}} 7.22010$ El Mayor-Cucapa earthquake along the Laguna Salada-Pescadores-Borrego-Paso Superior fault zone (Fletcher et al., 2010).

Following the 1940 earthquake, J. P. Buwalda visited the surface rupture along the Imperial fault between 24 May and 2 June, conducting numerous measurements and taking several photographs. The notes from his excursion were pre- served by C. R. Allen and are archived at Caltech. After the earthquake, low-altitude stereo-paired aerial photography was taken for $15 \mathrm{~km}$ of the most impressive part of the surface rupture, starting at the border; whereas to the south of the border, only scattered oblique aerials were flown. Furthermore, as much of the rupture in Mexico occurred in agricultural fields, detailed measurements of offset crop rows and other transitory features are forever lost. North of the border, however, the high-resolution, low-altitude photographs afford an opportunity to better characterize details of the rupture, and to explore topics such as slip variability, localization of slip, and rupture segmentation.

One note of caution here: although we have the exact dates of each of Buwalda's observations, we could find no information on the exact date the photography was flown. This aspect could be important in assessing differences between our measurements and those of Buwalda, as the Imperial fault sustained after slip following the 1979 earthquake rupture. We acquired two sets of photos, one from C. R. Allen at Caltech-presumably the same set that was used by R. P. Sharp as they were left to C. R. Allen by J. Buwalda-and a second set from A. G. Sylvester. Neither set had any date markings or other information that is usually stamped on such aerial photography. It was C. R. Allen's opinion (C. R. Allen, oral comm., 2012) that they were flown very soon after the earthquake, although we note that roads appear to have been repaired. Hence, at least a few days must have elapsed between the earthquake and the date of acquisition of the photography. It is also possible that they were flown at Buwalda's request after his field visit, but this is speculation. Buwalda visited the rupture between 24 May and 2 June 1940, a period of one to two weeks after the earthquake. Hence, although Buwalda's field observations and aerial photography were taken at about the same time period, within a few days to several weeks after the earthquake, we have not been able to isolate the precise dates of the photography as nobody survives who can confirm who ordered the flight (although Buwalda is a good candidate). In terms of after slip, much of the major effects would have already occurred by the time Buwalda made his field visit, as his observations did not begin until a full week after the earthquake. The aerial photography is from the same time period or slightly later if Buwalda was the one ordering the flight, or it could have been during his one-week sojourn to the rupture. In any case, as road repairs indicate some time lapse between the earthquake and photography, we consider them to be of approximately the same time frame during which the field measurements were made. Furthermore, it is likely that both imagery and field data represent coseismic slip, in addition to some after slip.

\section{Methods}

We acquired a set of the 1940 aerial photographs (scale, 1:7200) that were taken soon after the 18 May 1940 Imperial Valley earthquake and scanned them at 1200 dpi to produce 
the base upon which we mapped the rupture and determined slip distribution. The photos cover about $15 \mathrm{~km}$ of the total $60 \mathrm{~km}$ of surface rupture from the border region to the northwest, which includes the section of faulting with the greatest recorded displacements.

\section{Determination of the Precise Scale of the Aerial Photography}

We determined the precise scale for the aerial photographs by measuring the distance between field boundaries $(0.25$ miles or $\sim 400 \mathrm{~m})$ and other man-made structures and then comparing them with the identical features in Google Earth that have been preserved intact today. We made measurements only in the central $(50 \%-60 \%)$ portion of the stereo pairs, as the effects of parallax are minimal in this part of the imagery. For the 1940 images, we measured several field widths along the length of the flight line that have not recognizably changed between 1940 and 2011. We then constructed scales for each measurement to compare these estimates. All scale estimates were within about $1 \%$ agreement, and we took the average of these scales for our final scale to be used in measuring distances and offsets.

We used this scale in two ways. First, we made a linear, cumulative determination of the location of each offset feature starting from the middle of the All-American Canal adjacent to the international border. An error in the scale would produce a cumulative error in distance along the fault strike. We tested our scale by independently measuring distinctive cultural features in Google Earth from their location to the canal's center and determined that they agreed to within me- ters across distances of 5-15 km (0.1\%). We field checked this with a handheld GPS ( $\pm 3-4$ m uncertainty), which gave the same distance as measured in Google Earth. Based on these observations, we consider our scale validated and accurate to better than $1 \%$.

The largest uncertainty in the data set is the determination of the alignment of a crop or tree row, road, canal, or other feature, which we assume was relatively straight prior to the earthquake. We used a straight-line segment to place along a feature on one side of the fault, and copied the segment to maintain a parallel line for the same feature across the fault (Fig. 2). The line width is estimated at $\sim 10 \mathrm{~cm}$, which is approximately the smallest increment of displacement that could be measured from the 1940 imagery. The larger source of uncertainty is the actual placement of the line along a feature, which is dependent as to how straight and sharp the feature was expressed in the imagery and how far it could be extended beyond the near-field fault zone. In most cases with crop rows, the plow lines were found to be remarkably straight and well defined outward from the fault for tens to hundreds of meters, and straight-line segments were easy to place along the middle or edge of a crop row (Fig. 2). The uncertainties in displacement measurement are estimated to be no larger than $0.5 \mathrm{~m}$, considering all error sources (see Rockwell et al., 2002), but this, in effect, allows for hundreds of alignment arrays to be measured along the strike of the fault to assess lateral slip variability with reasonably small uncertainties.

We measured each offset feature three times at slightly different azimuths to test the significance in performing these types of measurements. The most reliable, and the one we

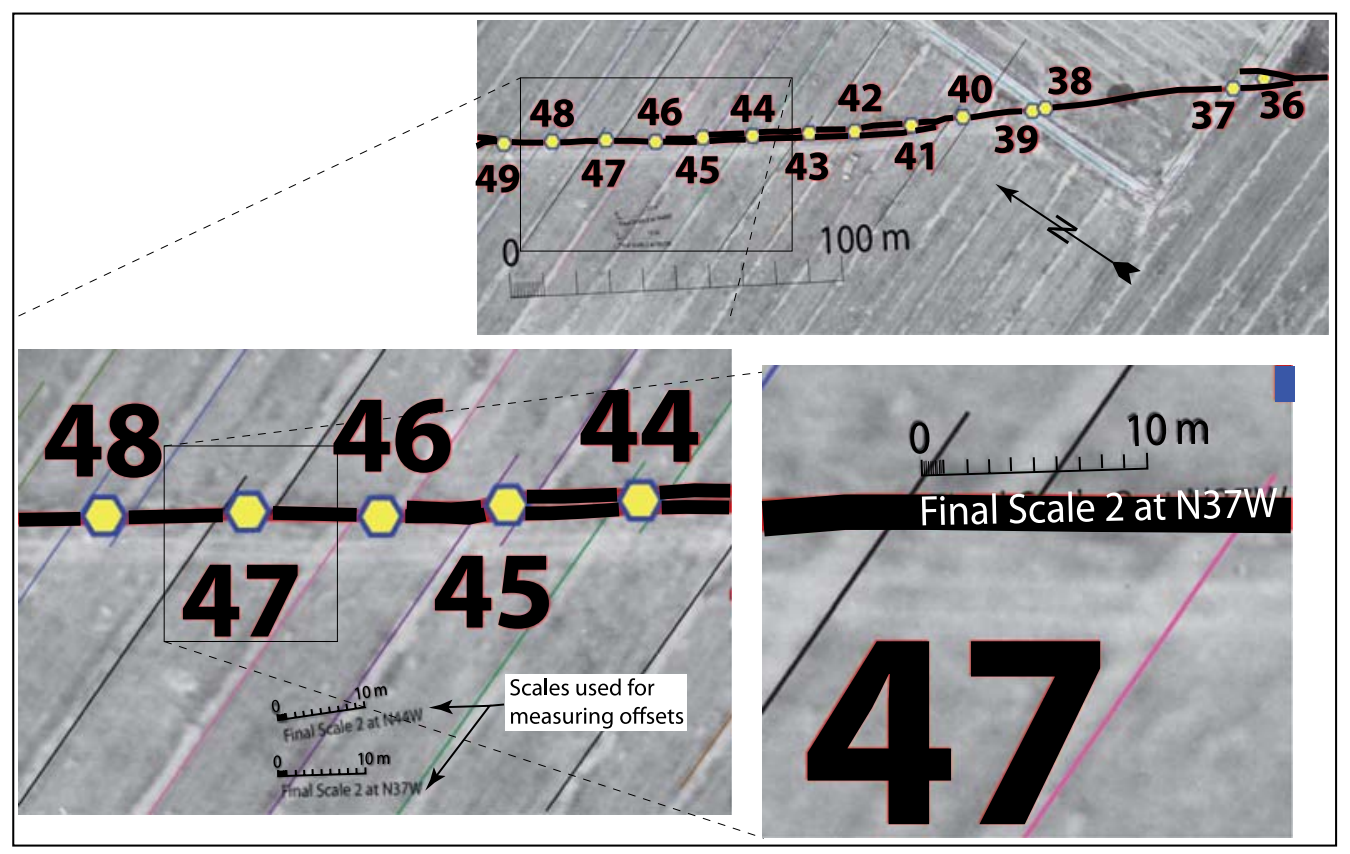

Figure 2. Example of parallel-line placement along features offset across the 1940 rupture trace. The detail shows the scales used to measure displacement parallel to $\mathrm{N} 44^{\circ} \mathrm{W}$ and $\mathrm{N} 37^{\circ} \mathrm{W}$. The offsets are resolvable to $10 \mathrm{~cm}$, when enlarged to the maximum resolution in Adobe Illustrator. The color version of this figure is available only in the electronic edition. 
use for the final slip distribution, are those taken parallel to the average strike of the fault at $\mathrm{N} 37^{\circ} \mathrm{W}\left(323^{\circ}\right)$. We prefer the measurements along the average fault strike for our final slipdistribution model because geodetic estimates of offset in the 1940 earthquake (King and Thatcher, 1998) demonstrate that the average vertical displacement was very small, $\sim 10 \mathrm{~cm}$. Thus, the average fault strike should provide the best estimate of actual slip in the earthquake. We also took measurements at $\mathrm{N} 44^{\circ} \mathrm{W}\left(316^{\circ}\right)$, which is parallel to the average regional plate motion, as well as measurements parallel to the local fault strike at the offset feature. This last measurement was performed because that is the displacement value that is commonly taken in the field by geologists (near-field perspective) when measuring offset after an earthquake, and it is interesting as a comparison.

\section{Observations}

Comparison to J. P. Buwalda's Field Measurements from his Field Notes

As a first test of our methods, we located the sites of Buwalda's field measurements that were made soon after the 1940 rupture, of which there were only five along the $15 \mathrm{~km}$ of rupture captured in the aerial photography. Some of these measurements were made on fence lines that we could not identify in the aerial imagery, but we were able to measure roads and canals that were immediately adjacent to the fence line instead. Some sites also had multiple measurements, with one along a north-south feature and another along an east-west feature. Figure 3 shows our slip estimates versus Buwalda's field measurements. In all cases, Buwalda performed his measurements perpendicular to the trend of the measured feature, all of which were either east-west or north-south, as all of the local farmlands are laid out in an orthogonal grid pattern. In contrast, we used our measured displacements that are parallel to the average strike of the fault $\left(\mathrm{N} 37^{\circ} \mathrm{W}\right.$, or a bearing of $\left.323^{\circ}\right)$ to construct Figure 3. We trigonometrically corrected our offset measurements to the same reference frame used by Buwalda's to compare the two sets. Our measurements agree closely to those of Buwalda's in most cases, but some tended to be slightly larger. These discrepancies are expected either because field surveyors lack the perspective needed to properly identify piercing lines, which is not the case when measuring from aerial photography (Klinger et al., 2005), or because we are measuring displacement across straight-line projections that extend tens of meters from the rupture trace and likely capture any near-field warping and other deformation associated with the rupture, as was seen with the 1999 Izmit rupture (Rockwell et al., 2002). In particular, Buwalda reports the offset of fence lines along Highway 98 (site B1a) but only reports a single strand, whereas two strands are clearly evident in the imagery for the east-west alignment, and there is a step in the fault trace. We measured the far-field displacement and resolved a slightly larger value for the east-west alignment, in addition to a nearly identical value for the north-south fence line where only a single fault strand exists. The other discrepancy is at site 6, where Buwalda measured fences along east-west and north-south alignments. Because we were unable to identify the fence lines, we took the four closest points for each alignment and averaged them for our measurement. We should note that our values at this site had a range of approximately a factor of two, as displacement varied significantly across short distances. Thus, we suspect that the primary difference in our estimates of displacement at this site is that we did not measure exactly the same feature, resulting in slip values that are larger than Buwalda's

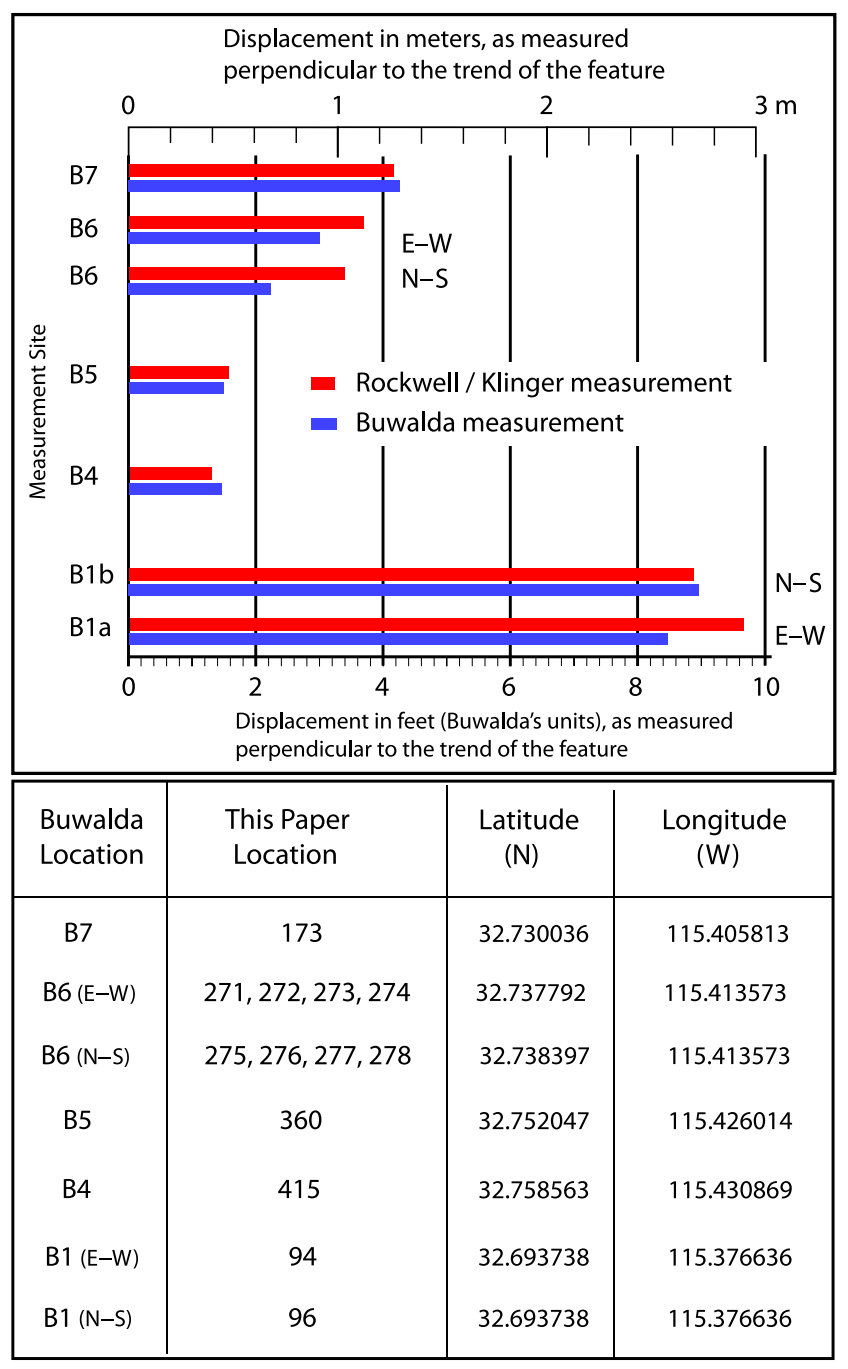

Figure 3. Comparison of the field measurements of J. P. Buwalda (1941; lower bars) with our estimates (upper bars) for points included in the area of aerial photograph coverage. It is worthy to note that the main discrepancy is from site B1 at Highway 98, where Buwalda reports a single fault trace. However, two traces are clearly visible in the imagery at a small step over. Site B6 also shows more displacement in our analysis, but we averaged four points for each measurement because we could not identify the fence lines used by Buwalda. The table provides the coordinates of Buwalda's measurements, along with our corresponding points. The color version of this figure is available only in the electronic edition. 
in Figure 3. Overall, we consider our measurements in close agreement with those of Buwalda.

\section{Slip Distribution}

To measure displacements, we started at the international border and established a line parallel to the rupture from which we established kilometer posts, or distances, from the center line of the All-American Canal to each feature (E) Fig. S1, available in the electronic supplement to this article). These locations were later put into a common reference frame with the offsets measured after the earthquake by Buwalda. Each offset was assigned a number, starting with 1 at the canal and increasing numerically to the northwest (E) Figs. S1 through $\mathrm{S} 7$, available in the electronic supplement to this article). Next, we systematically measured displacement for each feature along the three azimuths described above (these are listed in (E) Table S1, available in the electronic supplement to this article).

Figure 4 shows the slip distribution for the 1940 earthquake from our new measurements, along with J. P. Buwalda's 1940 field measurements (corrected to a bearing of $323^{\circ}$ ) and additional measurements from Sharp (1982), both shown as dots within a circle (bull's-eye). Finally, we surveyed a line of telephone poles that were erected prior to the 1940 earthquake at Tamaulipas and resolved $2.7 \mathrm{~m}$ of right-lateral strike-slip toward the southern end of the Imperial fault (star). In addition, we include the surveyed line of offset trees from Thomas and Rockwell (1996) just south of the border.
Our new data increase the number of slip observations for the 1940 surface rupture by more than one order of magnitude, although the majority of them are on the high-slip section of the fault that represents only $25 \%$ of the full length of the rupture.

An interesting feature in the slip-distribution curve is that displacement decreases or falls to zero at several points along the rupture. This was evident in the north, where displacement drops to zero or 13 and $23 \mathrm{~km}$ north of the All-American Canal (Sharp, 1982). Based on our new measurements, displacement also appears to drop significantly near kilometer post 5 at which, as shown previous slip distributions, an area without data or slip was shown to be increasing southward.

\section{Maximum Displacement}

Maximum displacement for the 1940 earthquake exceeded the reported $6 \mathrm{~m}$ of lateral displacement by about a meter. In the same general vicinity as the $6 \mathrm{~m}$ measurement of Sharp (1982), we determined that both edges of a road adjacent to a field were offset close to $7 \mathrm{~m}$ (Fig. 5). Slip decreased in both directions to between 4.5 and $6.5 \mathrm{~m}$ (Fig. 6), similar to the variability in lateral displacement that we observed along the entire photographed portion of the rupture; many measurements along this section exceeded $6 \mathrm{~m}$. These variations are also similar in magnitude to those reported by Rockwell et al. (2002) after the 1999 Izmit and Duzce earthquake ruptures. From these observations, we estimate that

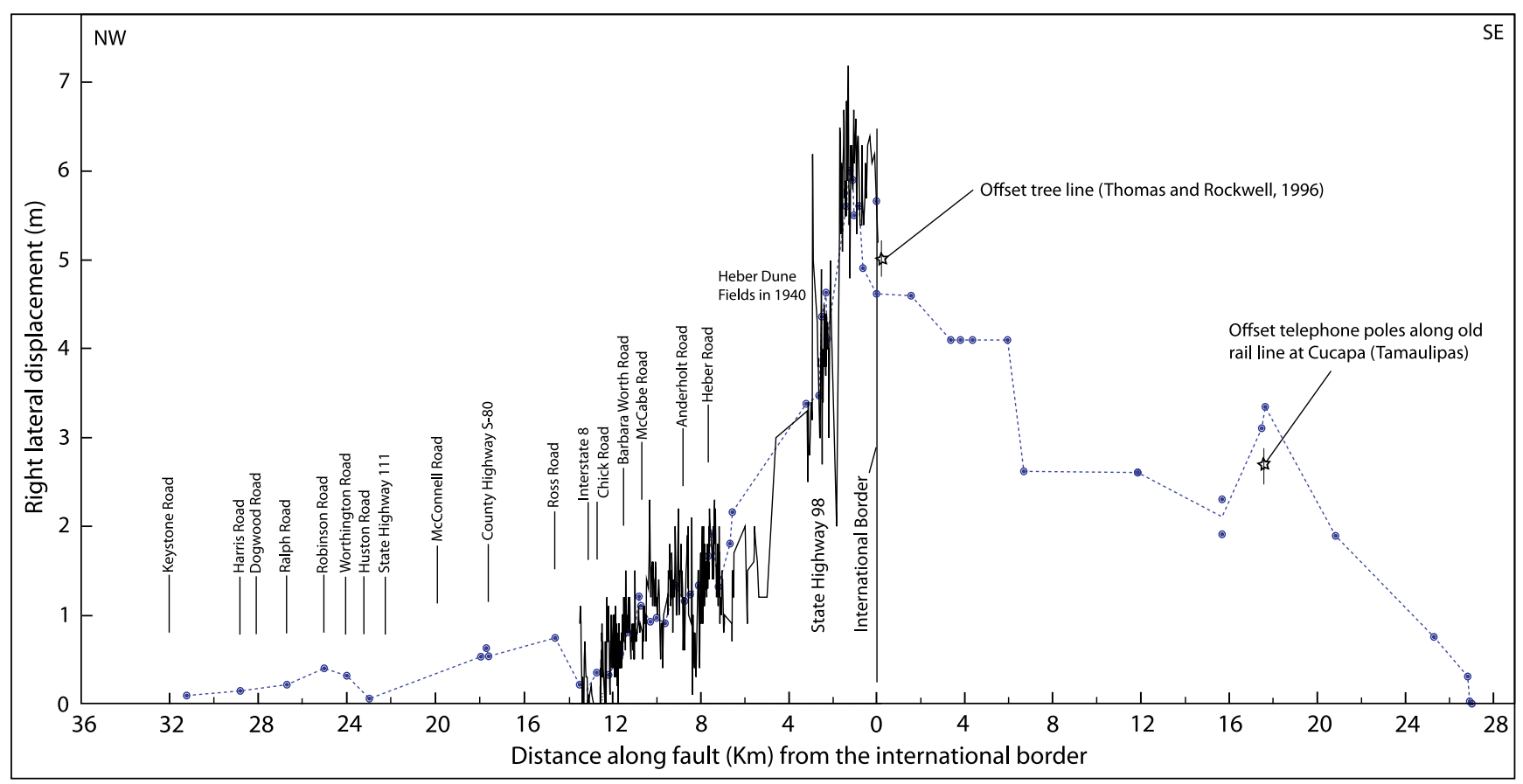

Figure 4. Slip distribution for the 1940 Imperial fault rupture. Our new observations are between the international border (zero point) and $\sim 14 \mathrm{~km}$ north of the border. The field measurements of J. P. Buwalda along with those of Sharp (1982) are plotted as dots within circles (bull's-eyes). The offset tree line in Thomas and Rockwell (1996) is shown as a star near the border, and our surveyed measurement of an offset telephone line is the star about $18 \mathrm{~km}$ south of the border. The color version of this figure is available only in the electronic edition. 
$\sim 7 \mathrm{~m}$ of maximum displacement in 1940 was located $\sim 2 \mathrm{~km}$ northwest of the international border. However, the average displacement along this $2-\mathrm{km}-$ long section was close to $5.5 \mathrm{~m}$.

\section{Lateral Variability of Displacement}

Measurement of long cultural features, such as crop rows, tree lines, roads, and fences, ensures that total near- field displacement will be captured in our measurements. In fact, as discussed in the subsequent section, nearly all of the displacement occurred in a very narrow zone of $5 \mathrm{~m}$ or less. Thus, by measuring numerous, closely spaced features, the magnitude of lateral variability can be assessed. For the 1940 surface rupture, Figure 4 shows that significant lateral variations in displacement are real and that they occur across

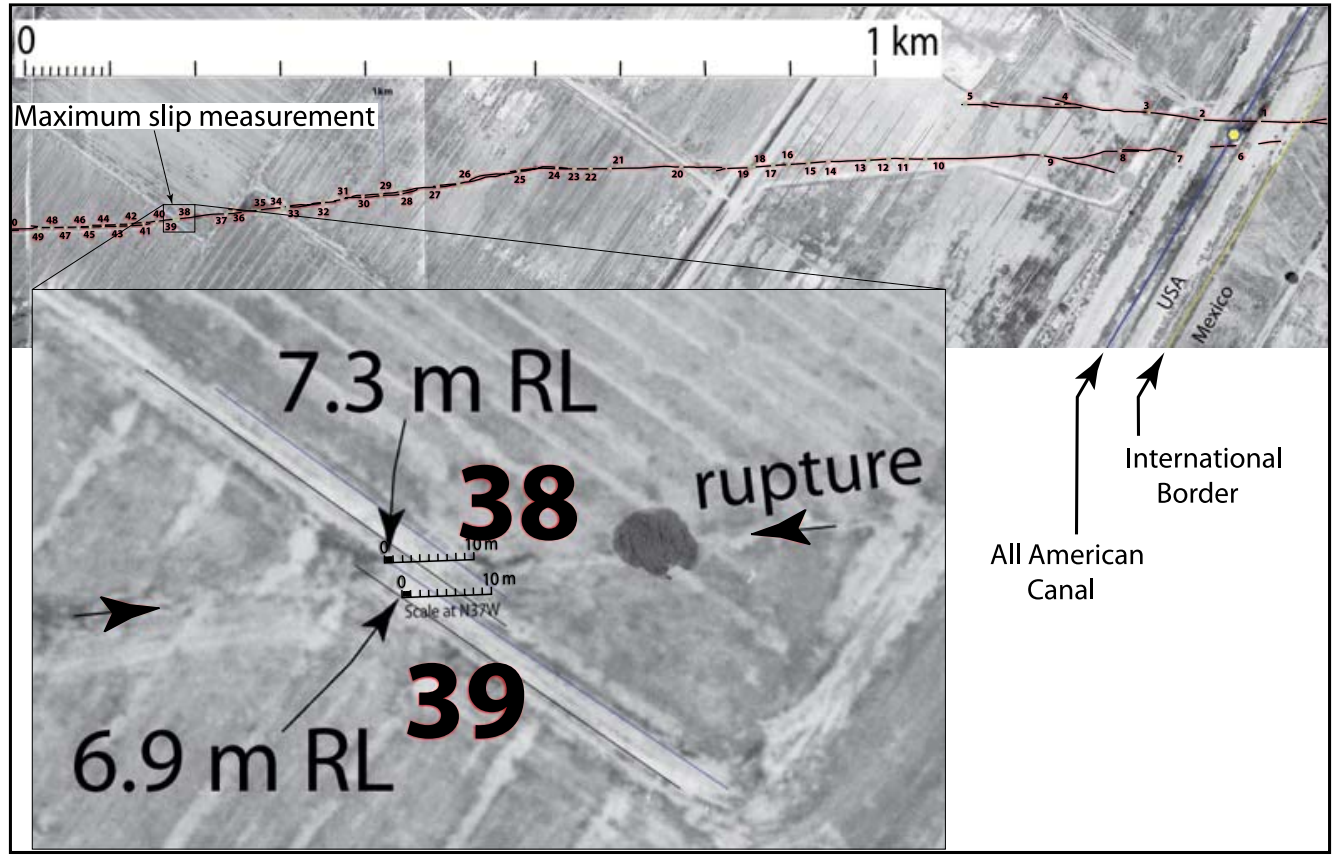

Figure 5. The 1940 rupture along the Imperial fault north of the international border. The All-American Canal is mere meters north of the border. About $2 \mathrm{~km}$ northwest from the border, a road/field boundary is offset about $7 \mathrm{~m}$, which is the maximum displacement that we found along the 1940 rupture. R. P. Sharp measured $\sim 6 \mathrm{~m}$ near the border, whereas J. P. Buwalda measured only $\sim 5 \mathrm{~m}$ across one of the two strands. The detail shows the offset, with scale included, at our measurement points 38 and 39. The color version of this figure is available only in the electronic edition.

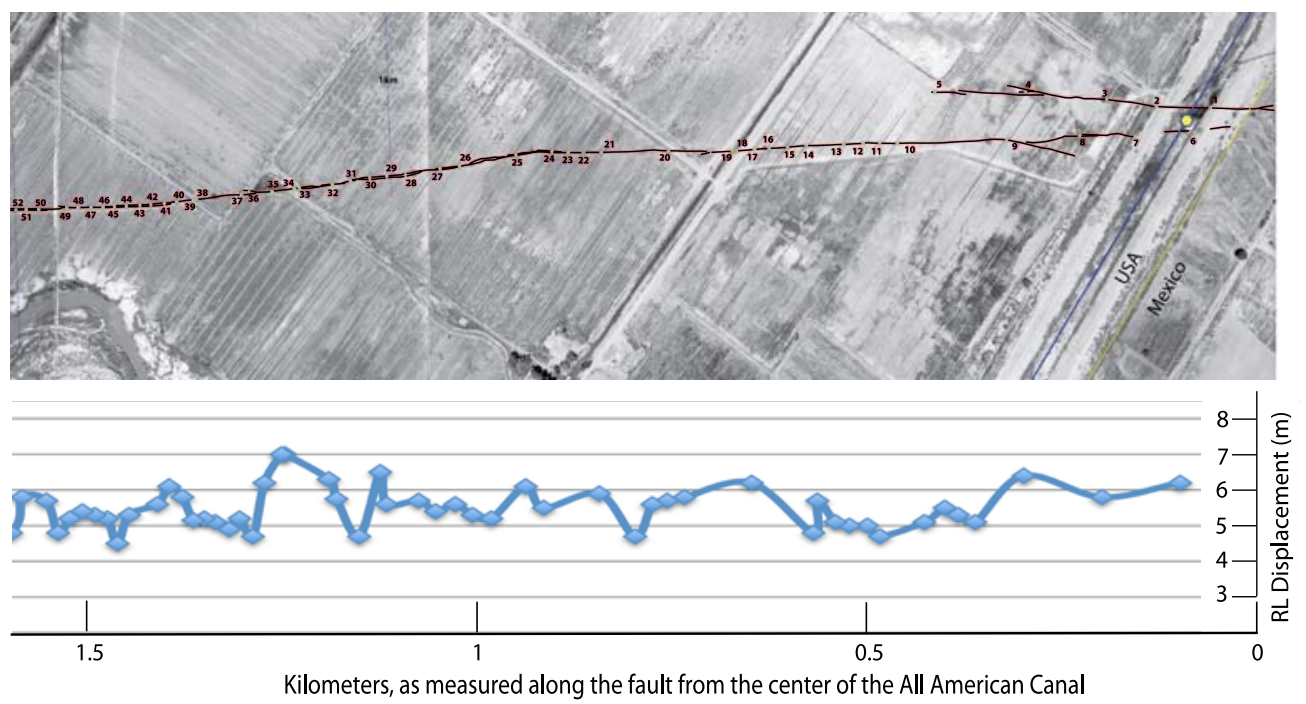

Figure 6. Slip distribution in the area of high slip. Note the significant amount of lateral variation in slip (measured at an azimuth of $\mathrm{N} 37^{\circ} \mathrm{W}$ ); measurement uncertainty is estimated at $50 \mathrm{~cm}$ or less. Several measurements exceeded $6 \mathrm{~m}$, which is the generally accepted value for maximum displacement prior to this research. The color version of this figure is available only in the electronic edition. 
short spatial dimensions. For instance, we determined displacement for adjacent rows of trees and crops for entire fields. In some cases, as in Figure 7, the variability occurs at $\sim 0.5 \mathrm{~m}$, our estimated resolution of displacement uncertainty. In this case, we measured the offset of individual tree lines to vary by about $1 \mathrm{~m}$ across a lateral distance of a few hundred meters, similar to the variability of offset tree lines in the Izmit earthquake. However, the argument could be made that these measurements are in agreement within the stated uncertainty. However, other examples, as in Figure 6, clearly express variability that is well beyond the uncertainties in the measurements and displays significant lateral variability. Figure 8 shows an example along the northern third of the 1940 rupture where the degree of displacement was less. In this case, closely spaced, arrow-straight crop rows could be resolved and measured to $\sim 10 \mathrm{~cm}$, with uncertainty estimated here at only $\sim 20 \mathrm{~cm}$. In this case, lateral slip varied from zero to more than $1 \mathrm{~m}$ along this several hundred-meter section of rupture (Fig. 8).

The overall degree of variability along the strike for the 1940 rupture is evident in the slip-distribution curve in Figure 4. Areas of larger offset tend to have greater absolute variations in displacement. That is, slip varied by more than $1 \mathrm{~m}$ along sections that sustained 5-7 $\mathrm{m}$ of displacement. However, along sections with less-average displacement, the magnitude of variability was less. From these observations, we conclude that lateral variability of displacement typically varies by as much as $30 \%$ along a section of the rupture.

\section{Localization of Displacement}

Linearity in the hundreds of crop rows allowed for an assessment of off-fault deformation, or the lack of it. In virtually all cases along the rupture where we can establish linearity of crop rows for tens to hundreds of meters out from the fault, there is very little to no bending of the furrows,

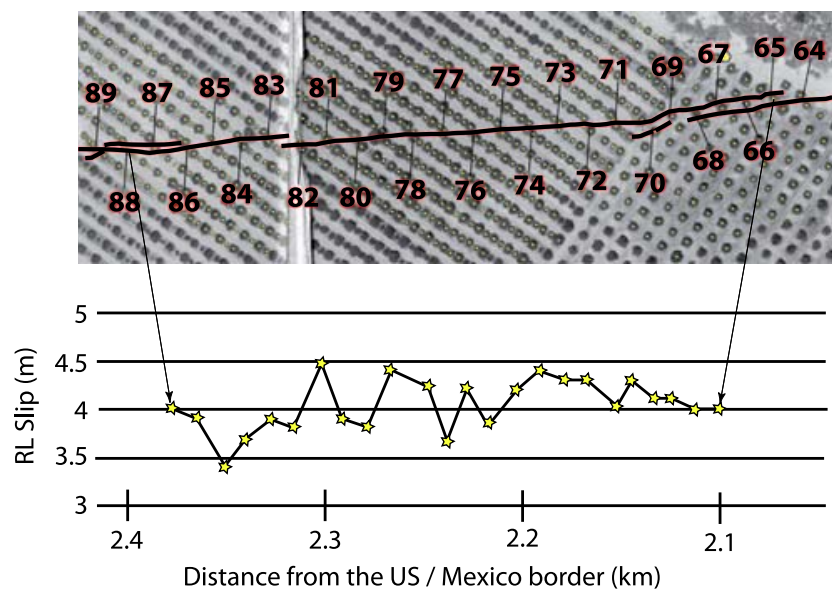

Figure 7. Offset grove of trees between 2.1 and $2.4 \mathrm{~km}$ northwest of the international border. A dot was placed on the center of each tree, and the dots were regressed to resolve lateral displacement. Uncertainty is estimated at $\sim 0.5 \mathrm{~m}$. The color version of this figure is available only in the electronic edition. roads, or other features beyond a 5-m-wide zone that captures the rupture. The rupture appears quite localized, and the crop rows are parallel on each side, which seem to indicate no recognizable distributed deformation. This is in marked contrast to the surveyed cultural features, including tree alignments, along the Izmit and Duzce ruptures (Rockwell et al. 2002), where bending or off-fault deformation accounted for up to $40 \%$ of the lateral slip and averaged $\sim 15 \%$. In the case of the Izmit and Duzce ruptures, the warping occurred almost exclusively on the down-thrown side of the fault where sediment is thickest (Rockwell et al., 2002). In the case of the Imperial fault, sediment is extremely thick (up to $10 \mathrm{~km}$ ) on both sides of the fault, so the lack of offfault warping is somewhat surprising, as is the apparent localization, which is more common for faults with shallow bedrock (Rockwell and Ben-Zion, 2007).

\section{Discussion}

Based on the collection of 648 new displacement measurements from the 1940 surface ruptures along the Imperial fault, several generalizations can be made. First, the sparse field data from the 1940 earthquake, nearly all of which was

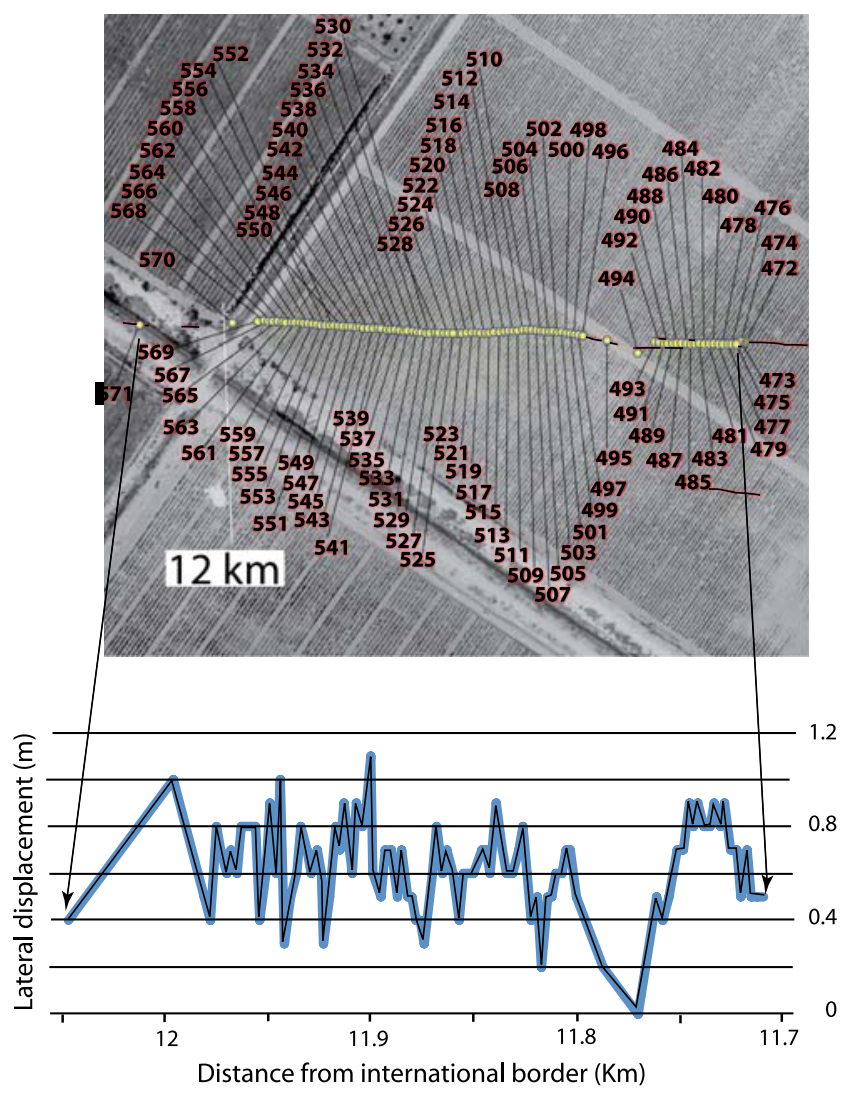

Figure 8. Offset crop rows between 11.7 and $12 \mathrm{~km}$ northwest of the international border. Crops rows could be measured to 10$15 \mathrm{~cm}$ of resolution because they had recently been planted and were not yet mature, but offsets vary by more than $1 \mathrm{~m}$. The color version of this figure is available only in the electronic edition. 
collected at convenient road crossings, missed the maximum displacement of $\sim 7 \mathrm{~m}$, as well as the maximum displacement along strike, although most of the field observations fall near the average displacement for a section of fault. It is evident from this analysis that dense collection of displacement data is required to quantify the maximum displacement along a rupture and that sparse data likely miss such displacement peaks and other details of the rupture.

The slip distribution for the 1940 Imperial Valley earthquake surface rupture displays many features that are important in understanding the rupture process. In this discussion, we first assess the significance of the azimuth, along which slip is measured in the field by geologists after a rupture. We then discuss the variability of lateral displacement, which may reflect a fundamental aspect of the rupture process. As determined from seismological data, we further compare the slip distribution to information about the complex energy release reported for that event to assess the segmentation of this relatively straight and simple fault, and to make inferences regarding shallow versus deep slip.

\section{Effect of Local Versus Average Fault Strike in Measuring Slip}

We measured displacement along three azimuths to test the effect of local variations in fault strike and displacement, as well as assess to what degree these factors play a role in the ability of geologists to measure the displacement field of a rupture after an earthquake. Part of this question arose from the numerous measurements that various groups of geologists made on the offset of Bessermine and Quail Lake roads after the 1992 Landers earthquake (McGill and Rubin, 1999), where estimates of displacement based on the offset of the same feature varied considerably. We suspect that a significant part of the variation in offset values is primarily related to three things: the orientation of the feature (in their case, a dirt road), the sharpness and clarity of the feature being measured (poorly defined dirt road edge), and the orientation/azimuth of the slip measurement (i.e., whether the measurement was taken along the local fault strike or regional fault strike, or neither).

Figure 9 shows a comparison between the 648 measurements made at an azimuth of $\mathrm{N} 37^{\circ} \mathrm{W}$ (average fault strike) versus those taken along the local fault strike. The average difference for all measurements is $-0.01 \pm 0.19 \mathrm{~m}$, suggesting to us that although the choice of local fault strike may over- or underestimate local displacement by as much as $1 \mathrm{~m}$, the overall effect on measuring displacement for an entire rupture is negligible. We also note that the difference in measurements between these two azimuths varies as a function of the amount of displacement; we note larger differences along the section of rupture with larger displacement. We conclude from this that it is probably better to perform measurements parallel to the average strike of the fault to best characterize maximum displacement and local variations in displacement, but average displacement is well characterized by either method as long as one is consistent.

\section{Lateral Variations in Displacement}

Until the advent of pre- and postearthquake comparisons of LiDAR and optical imagery data, most measurements of lateral displacement along strike-slip faults after large earthquakes were conducted on near-field, nonlinear features such as rills, stream channels, channel margins, bars, and other common geomorphic features (Clark, 1972; Sharp, 1982; Sieh et al., 1993; Barka et al., 2002; Treiman et al., 2002). Observations of significant lateral variations in displacement across short spatial dimensions have been reported for several other large earthquakes, as observed from field mapping in the 1987 Superstition Hills earthquake (McGill et al., 1989; Sharp et al., 1989), the 1992 Landers earthquake (Sieh et al., 1993), and the 1999 Hector Mine, Izmit, and Duzce earthquakes (Barka et al., 2002; Rockwell et al., 2002; Treiman et al., 2002). For field measurements, slip was typically determined on small geomorphic features, among them channel margins, channel thalwegs, alluvial bars, and canyon walls, none of which were linear for any distance from the fault. Consequently, near-field, off-fault deformation could not be assessed, and it was generally assumed that some of the variability was the result of nonquantified offset. However, Rockwell et al. (2002) used surveyed cultural features (trees, fence, walls, and canals) that were offset in the 1999 Izmit and Duzce earthquakes to show that this lateral variability could not be attributed simply to missed near-field displacement. Further, modern techniques in geodesy (optical correlation techniques) were used for the 2001 Kunlun earthquake (Klinger et al., 2006) and the $2010 \mathrm{El}$ Mayor-Cucapah earthquake (Hudnut et al., 2010) that also display these lateral variations. They cannot be attributed to missed near-field slip but, rather, are actual variations in displacement. These variations are likely averaged out over

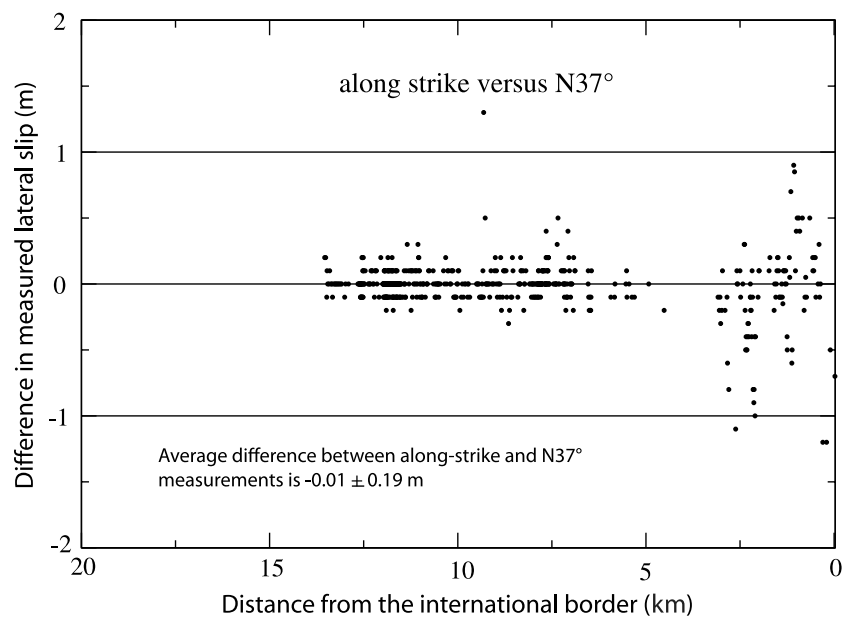

Figure 9. Difference between the displacements measured along the average $\left(\mathrm{N} 37^{\circ} \mathrm{W}\right)$ versus that along the local strike of the fault. The sum difference is $-0.01 \pm 0.19$. Note that, as expected, larger variability exists where displacement is larger. 
several earthquakes but should be considered when trying to estimate magnitude from geomorphic features that resulted from past ruptures.

\section{Absence of Off-Fault Deformation?}

In this study, we document significant lateral variations in displacement on offset crop rows, where the variability substantially exceeds our uncertainty in the measurement. The use of long agricultural features as closely spaced alignment arrays allows for both the assessment of total slip at a point along the fault, as well as the lateral variability of displacement along the fault. The variability that we document here is similar in magnitude and spatial scales to those documented after the Izmit and Duzce earthquakes, as well as more recently with optical imaging techniques after the 2010 El Mayor-Cucapah earthquake in northern Baja California (Hudnut et al., 2010). It is also worthy to note that we searched for significant off-fault warping, as was documented after the Izmit earthquake (Rockwell et al., 2002) but could determine no significant warping outside of a 5-mwide band along the fault, which encompassed the width of the rupture and zone of secondary cracking. We find this surprising, considering the depth of alluvium in the Imperial Valley, although we cannot preclude very broad warping that would still allow for the crop rows to remain parallel across the fault in the near field. We note that the Superstition Hills event also appears to have had a highly localized surface trace; it is noteworthy in that both faults ruptured up through many kilometers of sediment.

\section{Slip Distribution and Energy Release}

The 1940 earthquake is interpreted to have occurred in as many as 11 subevents, with the first four producing most of the moment release (Trifunac and Brune, 1970). These authors suggest that the mainshock sequence proceeded from northwest to southeast, with the fourth subevent releasing the most energy, based on analysis of a strong ground-motion seismometer record at nearby El Centro. Doser (1990) used body-wave inversions to study the source parameters and also concluded that the earthquake was composed of four main subevents.

The slip-distribution curve (Fig. 4) is characterized by several subsections that may reflect the subevents documented for the mainshock sequence. We interpret areas where displacement decreases significantly or falls to zero to be segment boundaries that reflect the endpoints of the subevent ruptures. In Figure 10, we break the rupture distribution into four subsegments by drawing triangles to encompass the displacement values, with the northwestern most two triangles being combined as they only represent $5 \%$ of the total area described by our subevent triangles. (We used triangles, as they fit as well as ellipsoids and they made it simple to measure the area beneath them.) A unique feature of the 1940 event is the mismatch between the location of the zone of maximum slip and the region of maximum radiated seismic energy. In the top of Figure 10, we show the location of the different subevents identified by Trifunac and Brune (1970) and by Doser (1990), along with the percentages of the total energy each subevent represents in each study. In the case of Trifunac and Brune (1970), some of the subevents were grouped, as they are roughly located along the same section of fault. It seems clear that the maximum slip area is located in the vicinity of the international border, whereas both seismological phenomena point to the majority of radiated seismic energy being farther south. We interpret this to imply that the slip measured at the surface in the area of maximum offset cannot be extended down-dip, or it would necessarily increase the seismic moment attributed to this subevent. Consequently, we infer that the zone of very high slip in the border region is likely a surficial feature. Considering that the overall length of the rupture is only $60 \mathrm{~km}$, which is fairly short for maximum displacement in this range (Wells and Coppersmith, 1994), this also supports our contention that the nearly $7 \mathrm{~m}$ of slip observed north of the border is not representative of slip at depth.

Although it is generally agreed that surface displacement is either similar to or less than that inferred to have occurred at depth in most earthquakes, the very high displacements may reflect a shallow asperity that only ruptures with the largest Imperial earthquakes. This idea is supported by the observation that the $M_{\mathrm{w}} 6.515$ October 1979 Imperial fault earthquake nucleated in Mexico south of the section with high slip and ruptured to the northwest underneath the several kilometers of large displacement (Archuleta, 1984). In fact, surface rupture in 1979 is only reported north of the

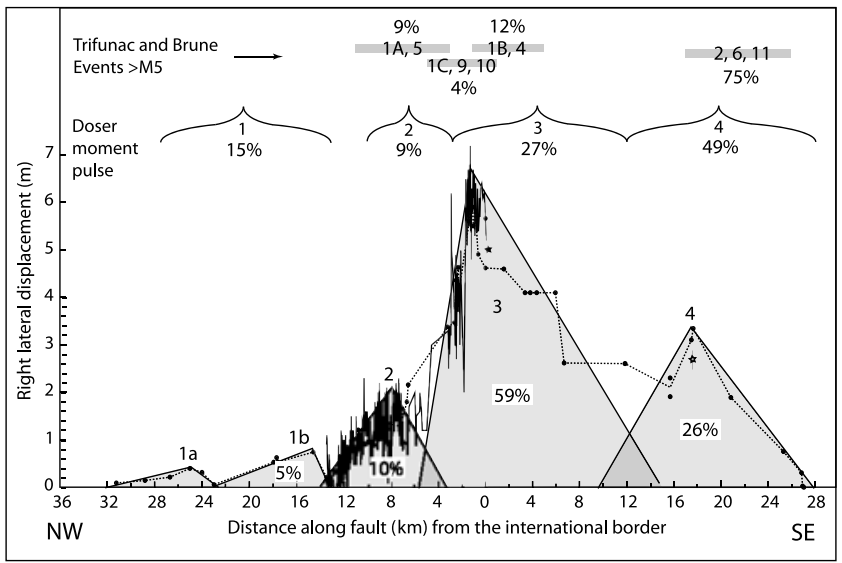

Figure 10. Triangles placed over interpreted rupture segments. The boundaries of the segments are interpreted where displacement decreases significantly or falls to zero. The subevents of Trifunac and Brune (1970) and Doser (1990), along with their estimate of the percentage of total moment magnitude released in each subevent, are shown at the top, along with their inferred locations. The percentages indicated within the triangles represent the proportion of each cross-sectional area for each triangle, based on surface slip. Note that the middle segment has the largest area, and, therefore, inferred moment if based entirely on surface displacements. However, the southern segment was inferred to have released the largest moment, based on seismological data. 
zone of high displacement from the 1940 event (Sharp, 1982), consistent with the idea that the 1979 rupture occurred beneath an asperity in the border region. Geodetic modeling, in contrast, suggests that average displacement in the border region was $\sim 5 \mathrm{~m}$ in 1940 (King and Thatcher, 1998), but there is no geodetic control south of the border, where they infer displacement values that are half of those observed at the surface. The King and Thatcher model is inconsistent with seismological observations that indicate the largest moment release in the southern part of the rupture, and suggests that their estimate of $5 \mathrm{~m}$ of average slip may be too high. Again, this can be explained by a high-displacement shallow asperity with less average displacement at depth.

\section{Conclusions}

Analysis of early high-resolution aerial photography provides a means to remap and reanalyze older surface ruptures and to augment the database of well-resolved ruptures and their associated slip distributions. In this work, we used stereo-paired aerial photographs to significantly increase the number of slip measurements for the 1940 Imperial Valley earthquake, with the resulting slip distribution of sufficient detail to reveal information that likely relates to the complex rupture process documented for this historical event. As with other recent, well-documented surface ruptures, variations in lateral displacement are significant, with differences in slip as much as $30 \%$ across lateral distances of $1 \mathrm{~km}$ or less. We find that there is no significant difference in estimates of average slip when making measurements along the local fault strike or regional strike, as long as one is consistent. Finally, dense measurements of slip indicate the presence of segments, between which displacement decreases or falls to zero, and these segments apparently control the location and extent of the documented seismic subevents.

\section{Data and Resources}

Sources of data used in this paper are derived from the 1940 aerial photographs provided by A. G. Sylvester and from published sources in the References. All other data and observations are our own.

\section{Acknowledgments}

We thank Clarence R. Allen for access to the field notes of J. P. Buwalda, and Art G. Sylvester and Clarence R. Allen for copies of the 1940 aerial photographs. We thank Tim Dawson and Meng Wei for their thoughtful reviews of the manuscript. The Institut Physique du Globe de Paris (IPGP) partially supported T. K. Rockwell during his stay at IPGP, during which most of this work was conducted.

\section{References}

Archuleta, R. J. (1984). A faulting model for the 1979 Imperial Valley earthquake, J. Geophys. Res. 89, 4559-4585.

Barka, A., H. S. Akyuz, E. Altunel, G. Sunal, Z. Cakir, A. Dikbas, B. Yerli, R. Armijo, B. Meyer, J. B. Chabalier, T. Rockwell, J. R. Dolan, R. Hartlieb, T. Dawson, S. Christofferson, A. Tucker, T. Fumal,
R. Langridge, H. Stenner, W. Lettis, J. Bachhuber, and W. Page (2002). The surface rupture and slip distribution of the 17 August 1999 Izmit earthquake ( $\left.M_{\mathrm{w}} 7.4\right)$, North Anatolian fault, in Special Issue on the 1999 Izmit and Duzce, Turkey, earthquakes N. Toksoz (Editor), special issue, Bull. Seismol. Soc. Am. 92, 43-60.

Bennett, R. A., W. Rodi, and R. Reilinger (1996). Global positioning system constraints on fault slip rates in southern California and northern Baja, Mexico, J. Geophys. Res. 101, 21,943-21,960.

Buwalda, J. P., and C. F. Richter (1941). Imperial Valley earthquake of 18 May 1940, Geol. Soc. Am. Bull. 52, 1942-1943.

Çakir, Z., J.-B. de Chabalier, R. Armijo, B. Meyer, A. Barka, and G. Peltzer (2003). Co-seismic and early post-seismic slip associated with the 1999 Izmit earthquake (Turkey), from SAR interferometry and tectonic field observations, Geophys. J. Int. 155, 93-110.

Chen, Y., W. Chen, J. Lee, Y. Lee, C. Lee, H. Chang, and C. Lo (2001). Surface rupture of 1999 Chi-Chi earthquake yields insights on active tectonics of central Taiwan, Bull. Seismol. Soc. Am. 91, 977-985.

Clark, M. M. (1972). Surface rupture along the Coyote Creek fault, in The Borrego Mountain Earthquake of 9 April 1968, U.S. Geol. Surv. Prof. Pap. 787, 55-87.

Doser, D. I. (1990). Source characteristics of earthquakes along the southern San Jacinto and Imperial Fault zones (1937-1954), Bull. Seismol. Soc. Am. 80, 1099-1117.

Fletcher, J. M., T. K. Rockwell, O. J. Teran, E. Masana, G. Faneros, K. W. Hudnut, J. Gonzalez, A. Gonzalez, R. M. Spelz, K. J. Mueller, L. Chung, S. O. Akciz, J. Galetzka, J. M. Stock, and K. Sharer (2010). The surface ruptures associated with the El Mayor-Borrego earthquake sequence, Abstract SE05-1 presented at 2010 AGU Fall Meeting, EOS Trans. AGU, San Francisco, California.

Haeussler, P., D. P. Schwartz, T. E. Dawson, H. D. Stenner, J. J. Lienkaemper, B. Sherrod, F. Cinti, P. Montone, P. Craw, A. Crone, and S. Personius (2004). Surface rupture and slip distribution of the Denali and Totschunda faults in the 3 November $2002 M_{\mathrm{w}} 7.9$ earthquake, Alaska, Bull. Seismol. Soc. Am. 94, S25-S52.

Hudnut, K. W., J. M. Fletcher, T. K. Rockwell, J. J. Gonzalez-Garcia, O. Teran, and S. O. Akciz (2010). Earthquake rupture complexity evidence from field observations, Eos. Trans. AGU Fall AGU, T51E-02.

King, N.E., and W. Thatcher (1998). The co-seismic slip distributions of the 1940 and 1979 Imperial Valley, California, earthquakes and their implications, J. Geophys. Res. 103, no. B8, 18,069-18,086.

Kondo, H., Y. Awata, O. Emre, A. Dogan, S. Ozalp, F. Tokay, C. Yildirim, T. Yoshioka, and K. Okumura (2005). Slip distribution, fault geometry, and fault segmentation of the 1944 Bolu-Gerede earthquake rupture, North Anatolian fault, Turkey, Bull. Seismol. Soc. Am. 95, 1234-1249.

Klinger, Y. (2010). Relation between continental strike-slip earthquakes, segmentation, and thickness of the crust, J. Geophys. Res. 115, B07306, doi: 10.1029/2009JB006550.

Klinger, Y., M. Etchebes, P. Tapponnier, and C. Narteau (2011). Characteristic slip for five great earthquakes along the Fuyun fault in China, Nature Geosci. 4, no. 6, 389-392.

Klinger, Y., R. Michel, and G. C. P. King (2006). Evidence for an earthquake barrier model from $M_{\mathrm{w}}$ similar to 7.8 Kokoxili (Tibet) earthquake slipdistribution, Earth Planet Sci. Lett. 242, 354-364.

Klinger, Y., X. W. Xu, P. Tapponnier, J. Van der Woerd, C. Lasserre, and G. King (2005). High-resolution satellite imagery mapping of the surface rupture and slip distribution of the $M_{\mathrm{w}} 7.814$ November 2001 Kokoxili earthquake, Kunlun fault, northern Tibet, China, Bull. Seismol. Soc. Am. 95, 1970-1987.

Kurushin, R. A., A. Bayasgalan, M. Ölziybat, B. Enhtuvshin, P. Molnar, C. Bayarsayhan, K. Hudnut, and L. Jian (1997). The surface rupture of the 1957 Gobi-Altay, Mongolia, earthquake, Geol. Soc. Am. Special Paper 320, 143 pp., with plates.

McGill, S. M., and C. M. Rubin (1999). Surficial slip distribution on the central Emerson fault during the 28 June 1992 Landers earthquake, J. Geophys. Res. 104, 4811-4833.

McGill, S., C. Allen, K. Hudnut, D. Johnson, W. Miller, and K. Sieh (1989). Slip on the Superstition Hills fault and on nearby faults associated with 
the 24 November 1987 Elmore Desert Ranch and Superstition Hills earthquakes, southern California, Bull. Seismol. Soc. Am. 79, 362-375.

Mueller, K. J., and T. K. Rockwell (1995). Late Quaternary activity of the Laguna Salada fault in northern Baja California, Mexico, Geol. Soc. Am. Bull. 107, 8-18.

Oskin, M. E., J. R. Arrowsmith, A. H. Corona, A. J. Elliott, J. M. Fletcher, E. J. Fielding, P. O. Gold, J. J. Gonzalez Garcia, K. W. Hudnut, J. Liu-Zeng, and O. J. Teran (2012). Near-field deformation from the El Mayor-Cucapah earthquake revealed by differential LiDAR, Science 335, 702-705.

Peltzer, G., F. Crampe, and G. King (1999). Evidence of nonlinear elasticity of the crust from the $M_{\mathrm{w}}$ 7.6 Manyi (Tibet) earthquake, Science 286, 272-275.

Richter, C. F. (1958). Elementary Seismology, W.H. Freeman and Co., San Francisco, California, 768 pp.

Rockwell, T. (1990). Holocene activity of the Elsinore fault in the Coyote Mountains, southern California: I, in Western Salton trough soils and tectonics, Friends of the Pleistocene Guidebook, T. K. Rockwell (Editor), 30-42.

Rockwell, T. K., and Y. Ben-Zion (2007). High localization of primary slip zones in large earthquakes from paleoseismic trenches: Observations and implications for earthquake physics, J. Geophys. Res. 112, B10304-B10313, doi: 10.1029/2006JB004764.

Rockwell, T. K., S. Lindvall, T. Dawson, R. Langridge, W. Lettis, and Y. Klinger (2002). Lateral offsets on surveyed cultural features resulting from the 1999 Izmit and Duzce earthquakes, Turkey, Bull. Seismol. Soc. Am. 92, 79-94.

Salisbury, J. B., T. K. Rockwell, T. J. Middleton, and K. W. Hudnut (2012). LiDAR and field observations of slip distribution for the most recent surface ruptures along the central San Jacinto fault, Bull. Seismol. Soc. Am. 102, 598-619.

Sharp, R. V. (1982). Comparison of 1979 surface faulting with earlier displacements in the Imperial Valley, in the Imperial Valley, California, earthquake of 15 October 1979, U.S. Geol. Surv. Prof. Pap. 1254, 213-221.

Sharp, R. V., K. E. Budding, J. Boatwright, M. J. Ader, M. G. Ader, M. G. Bonilla, M. M. Clark, T. E. Fumal, K. K. Harms, J. J. Lienkaemper, D. M. Horton, B. J. O'Neill, C. L. Ortergren, D. J. Ponti, M. J. Rymer, J. L. Saxton, and J. D. Sims (1989). Surface faulting along the Superstition Hills Fault Zone and nearby faults associated with the earthquakes of 24 November 1987, Bull. Seismol. Soc. Am. 79, 252-281.

Sharp, R. V., J. J. Lienkaemper, M. G. Bonilla, D. B. Burke, B. F. Fox, D. G. Herd, D. M. Miller, D. M. Morton, D. J. Ponti, M. J. Rymer, J. C. Tinsley, J. C. Yount, J. E. Kahle, E. W. Hart, and K. E. Sieh (1982). Surface faulting in the central Imperial Valley, in the Imperial
Valley, California, earthquake of 15 October 1979, U.S. Geol. Surv. Prof. Pap. 1254, 119-143.

Sieh, K., and P. Williams (1990). Behavior of the southermost San Andreas fault during the past 300 years, J. Geophys. Res. 95, 6629-6645.

Sieh, K., L. Jones, E. Hauksson, K. Hudnut, D. Eberhart-Phillips, T. Heaton, S. Hough, K. Hutton, H. Kanamori, A. Lilje, S. Lindvall, S. McGill, J. Mori, C. Rubin, J. A. Spotila, J. Stock, H. K. Thio, J. Treiman, B. Wernicke, and J. Zachariasen (1993). Near-field investigations of the Landers earthquake sequence, April-July 1992, Science 260, 171-176.

Thomas, A., and T. K. Rockwell (1996). A 300- to 550-year history of slip on the Imperial fault near the U.S.-Mexico border: Missing slip at the Imperial fault bottleneck, J. Geophys. Res. 101, no. B3, 5987-5997.

Treiman, J. A., K. J. Kendrick, W. A. Bryant, T. K. Rockwell, and S. F. McGill (2002). Primary surface rupture associated with the $M_{\mathrm{w}} 7.116$ October 1999 Hector Mine earthquake, San Bernardino County, California, Bull. Seismol. Soc. Am. 92, 1171-1191.

Trifunac, M. D., and J. N. Brune (1970). Complexity of energy release during the Imperial Valley, California, earthquake of 1940, Bull. Seismol. Soc. Am. 60, 137-160.

Wells, D. L., and K. J. Coppersmith (1994). New empirical relationships among magnitude, rupture length, rupture width, rupture area, and surface displacement, Bull. Seismol. Soc. Am. 84, 974-1002.

Wesnousky, S. G. (2008). Displacement and geometrical characteristics of earthquake surface ruptures: Issues and implications for seismichazard analysis and the process of earthquake rupture, Bull. Seismol. Soc. Am. 98, 1609-1632.

Wright, T., E. Fielding, and B. Parsons (2001). Triggered slip: Observations of the 17 August 1999 Izmit (Turkey) earthquake using radar interferometry, Geophys. Res. Lett. 28, 1079-1082.

Geological Sciences, MC 1020

San Diego State University

San Diego, California 92182

trockwell@mail.sdsu.edu

(T.K.R.)

Institut de Physique du Globe de Paris

Sorbonne Paris Cité, Univ. Paris Diderot

UMR 7154 CNRS, 1 rue Jussieu

F-75005 Paris, France

klinger@ipgp.fr

(Y.K.)

Manuscript received 6 June 2012 